\title{
Artigos
}

\section{Do vínculo ao encontro cuidador: cartografias sobre o território identitário médico e o cuidado entre médicos de família e usuários}

From the bond to the caring encounter: cartographs about medical identity territory and the care between family doctors and users (abstract: p. 16)

Del vínculo al encuentro cuidador: cartografías sobre el territorio de identidad médico y el cuidado entre médicos de familia y usuarios (resumen: p. 16)

\section{Nicole Karina Nicolaiko Temperly(a) \\ <nkntemperly@gmail.com> (i)}

Helvo Slomp Junior ${ }^{(b)}$

<helvosj@macae.ufrj.br>

Milene Zanoni da Silva(c)

<milenezanoni@gmail.com>

\author{
(a) Pós-graduanda em \\ Psiquiatria (residência \\ médica), Pôle Santé Mentale, \\ site de Bellelay, Hôpital du \\ Jura Bernois SA, L'Abbaye 2 \\ 2713. Bellelay, Suíça. \\ (b) Curso de Medicina, \\ Universidade Federal do Rio de \\ Janeiro. Macaé, RJ, Brasil. \\ (c) Departamento de Saúde \\ Coletiva, Universidade Federal \\ do Paraná. Curitiba, PR, Brasil.
}

Estudo qualitativo com abordagem cartográfica que teve como objetivo compreender os efeitos que o vínculo e a responsabilização entre médicos de família e usuários produzem nos próprios médicos. Foram realizadas dez entrevistas abertas por meio de perguntas disparadoras com médicos de família e médicos residentes. A análise das entrevistas se deu sob o referencial da micropolítica e problematizou, com base nas experiências relatadas, a existência de um "território identitário médico", bem como as possibilidades de desconstituição desse território, sua desterritorialização no sentido de novas reterritorializações, a exemplo de afastar-se da onipotência/infalibilidade não para sofrer, mas para cuidar de si e do outro. Propõe-se que, nesse movimento de reconstrução do território identitário, tanto médico como usuário passem a transitar pela dimensão cuidadora do encontro, em que tecnologias leves podem ser operadas e novas possibilidades de configurações do cuidado acontecem.

Palavras-chave: Medicina de família e comunidade. Longitudinalidade do cuidado. Vínculo. Cuidado centrado no paciente. 


\section{Introdução}

A Medicina de Família e Comunidade (MFC) propõe, em seus princípios norteadores da especialidade, a valorização e o fortalecimento da relação médico-paciente ${ }^{1}$. Para tanto, ganha destaque o Método Clínico Centrado na Pessoa (MCCP), cuja proposta coloca em enfoque central a interação entre médico e paciente, levando em consideração as particularidades dos envolvidos e permitindo ao paciente um papel de protagonismo nessa relação ${ }^{2}$. Conforme proposto por $\mathrm{McWhinney}^{1}$ o médico de família deve buscar conhecer a pessoa antes de conhecer a doença, o que significa ser necessário lançar mão de recursos habitualmente utilizados nas relaçôes interpessoais, com seus aspectos subjetivos e imensuráveis, como a intuição, a empatia, as emoções suas e do outro. Para fins deste artigo, chamaremos de "leves" essas tecnologias relacionais, conforme apresentamos adiante ${ }^{3,4}$.

$\mathrm{Na}$ construção da relação entre médico de família e usuário, é de grande importância o caráter longitudinal do cuidado que o médico oferece em âmbito individual, familiar e comunitário. A longitudinalidade é definida como o acompanhamento do sujeito ao longo do tempo para finalidades diagnósticas, terapêuticas e preventivas, e é um dos atributos essenciais da Atenção Primária à Saúde (APS) 5 . Esse acompanhamento continuado permite múltiplos encontros entre médico e usuário, gerando oportunidades para aprofundar o entendimento sobre as características daquele sujeito e, assim, compreender que as inúmeras doenças de uma pessoa só fazem sentido quando reconhecidas em seu contexto pessoal, familiar e comunitário ${ }^{6}$. E, mais do que isso, é capaz de produzir um vínculo - uma conexão - entre médico de família e usuário, vínculo esse que surge e se mantém na interação que acontece em cada encontro entre esses atores, gerando sentimentos diversos em ambos e fortalecendo a ligação entre eles ${ }^{6,7}$.

O conceito de vínculo aparece em documentos relacionados à Atenção Básica $(\mathrm{AB})$ brasileira como instrumento operado na convivência entre os sujeitos e com potencial para o enfrentamento das questóes em saúde e sua manutenção $0^{8,9}$. É também compreendido como fator essencial na construção de relaçôes de confiança e proximidade entre usuários e trabalhadores da saúde, estimulando a corresponsabilização e intensificando o potencial terapêutico dos encontros em saúde ${ }^{10}$. Em uma revisão ${ }^{11}$ sobre o vínculo na Atenção à Saúde no Brasil, fala-se de um aprofundamento na compreensão dos problemas de saúde da população atendida por parte dos profissionais a ela vinculados, o que os motivaria a desenvolver um trabalho conjunto pela busca de soluções, facilitando assim a relação do usuário com o profissional.

No que diz respeito ao encontro entre médico e usuário, o contato entre esses atores na proposta de produção de saúde pode se tornar um encontro intercessor, no sentido de permitir o surgimento de um processo singular e que é um produto que se faz em ato, um espaço intercessor que só existirá nesses encontros ${ }^{3,4}$. Em palavras de Merhy ${ }^{4}$ :

[...] a imagem desse espaço é semelhante à da construção de um espaço comum, no qual um intervém sobre o outro, por isso é caracterizado como processo intercessor e não uma simples intersecção, pois contém na sua constitutividade a lógica da mútua produção em ato micropolítico, que supóe a produção de um no outro. (p. 173) 
Nesse âmbito podem ser operadas as dimensões tecnológicas do cuidar, a saber, as tecnologias duras, leve-duras e especialmente as leves ${ }^{3,4}$. As tecnologias duras e leve-duras constituem as modalidades hegemônicas, que englobam as açóes "profissional-centradas" por meio de intervençóes mais invasivas ou que dependem de equipamentos e recursos materiais (tecnologias duras), ou saberes especializados e intervençóes estritamente protocolares (leve-duras). As tecnologias leves são as tecnologias de relaçôes, e podem ser exemplificadas pela produção de vínculo, estímulo à autonomia, acolhimento e gestão como uma forma de organizar processos de trabalho no sentido de produção do cuidado. Em sua proposta, trazem uma maneira coletiva de se construir configuraçóes de cuidar com Atenção à Saúde "usuário-centrada”, e consequente construção compartilhada do cuidado ${ }^{3,4}$.

Grande parte dos estudos sobre os aspectos quantitativos da relação médico-usuário no contexto da APS evidencia um aumento na satisfação dos usuários que são acompanhados longitudinalmente por um médico de família de referência ${ }^{12-14}$. Além disso, tem sido descrito que o vínculo e a continuidade no acompanhamento de usuários podem produzir no médico de família um maior senso de responsabilidade por aquelas pessoas e satisfação profissional; e outros estudos mostram ainda sentimentos como o fortalecimento do senso de competência, embora também o desgaste emocional por diagnósticos difíceis e pela relação com usuários demandadores pode levar a um esgotamento psicológico e até mesmo à síndrome de burnout ${ }^{15,16}$.

Mais da metade dos médicos sofre ou já sofreu de sintomas relacionados ao esgotamento profissional, e em médicos de família a prevalência pode chegar a $60 \%{ }^{17,18}$. Entre os principais fatores desencadeantes ou agravantes desse esgotamento em médicos, destacam-se as inadequações dos processos de trabalho, sobrecarga, limitações e ambiguidade no desempenho de papéis, consultas carregadas de emoção, entre outros ${ }^{19}$. Por outro lado, fatores como uma boa relação com os usuários e se sentir reconhecido e valorizado pelo seu trabalho são relacionados com o sentimento de satisfação profissional, e por isso podem proteger o médico contra os efeitos físicos e psicológicos do estresse em longo prazo. E mais, quando o estresse se sobrepóe à satisfação profissional, o risco para a exaustão aumenta consideravelmente ${ }^{17,19}$. Qual seria, então, o papel do vínculo na produção de sentimentos desgastantes ou recompensadores para aqueles médicos de família que vivenciam uma relação longitudinal de cuidado com seus usuários? Seria o próprio vínculo um fator gerador de sobrecarga à medida que o médico intensifica a relação com o usuário e se sente responsável pelos desfechos de saúde da pessoa? Ou o potencial terapêutico e satisfatório que o vínculo tem para o usuário poderia ser extrapolado também para o médico?

Esta pesquisa, vinculada ao Programa de Mestrado Profissional em Saúde da Família (ProfSaúde), oportunizado pela Associação Brasileira de Saúde Coletiva (Abrasco) e instituições de ensino e pesquisa brasileiras, teve como objetivo compreender os efeitos que o vínculo e a responsabilização entre médicos de família e usuários podem produzir nos próprios médicos. Seu processo construtivo foi conduzido sob a ótica da micropolítica do cuidado e do trabalho em saúde. Ao longo do trabalho de campo assumiu-se uma abertura a novas questões que os próprios achados empíricos apontaram (como, por exemplo, a existência de um território identitário médico e as possibilidades 
de reestruturação desse território com base nas experiências permitidas pelo vínculo com o usuário). Esse caráter dinâmico do estudo esteve em conformidade com a estratégia metodológica escolhida, a abordagem cartográfica, que permite ao pesquisador imergir em seu campo de pesquisa e assim produzir conhecimento por meio dos afetos e intercessões oportunizados pelo encontro entre pesquisador e pesquisado ${ }^{20,21}$.

\section{Metodologia}

Trata-se de um estudo de caráter exploratório com abordagem qualitativa de orientação cartográfica. Foram realizadas dez entrevistas abertas com perguntas disparadoras (Quadro 1) a médicos de família atuantes na APS de Curitiba, Paraná, e médicos residentes em MFC da Universidade Federal do Paraná (UFPR) que atuassem há um ano ou mais na mesma comunidade, para garantir um mínimo grau de longitudinalidade necessário para o desenvolvimento do estudo. A escolha dos participantes se deu por indicação de profissionais das referidas instituições, com convite individual realizado pelos pesquisadores, escolhendo-se intencionalmente aqueles profissionais que eram descritos por seus pares como tendo uma relação de proximidade com seus usuários e comunidade. Foram entrevistados médicos de três diferentes grupos, segundo o critério de tempo de atuação na APS, a saber: 1) médicos residentes com dois ou três anos de prática em MFC;2) médicos jovens com até 15 anos de atuação na APS; e 3) médicos experientes, com mais de trinta anos de atividade profissional. Tal classificação dos participantes foi considerada na pesquisa como necessária para uma avaliação dependente de algum grau de longitudinalidade, e possibilitou o acesso a diferentes opiniốes e experiências.

Quadro 1. Perguntas disparadoras para as entrevistas abertas.

Na sua experiência clínica, ao se relacionar com usuários e famílias:

- Como você descreveria os efeitos emocionais em si mesmo, quando desenvolve uma relação mais

próxima com seus usuários ao longo do tempo?

- Você vivenciou efeitos recompensadores a partir dessa relação?

- E houve também efeitos desgastantes, paralisantes, frustrantes...?

- Que significado esses efeitos têm ou tiveram para você?

- Você gostaria de contar uma situação marcante para você?

Fonte: Os autores, 2018.

As entrevistas ocorreram entre os meses de janeiro e outubro de 2018, após obtenção de consentimento informado pelos participantes. Foram realizadas individualmente (um pesquisador entrevistou um participante em cada encontro), em ambientes escolhidos pelos participantes, onde pudessem ser garantidos o sigilo e a confidencialidade das informaçôes (por exemplo: consultório do participante, sala de reunióes da universidade, residência do participante). O material obtido nas entrevistas foi analisado pelos pesquisadores sob a ótica da abordagem cartográfica, que se propõe a valorizar processos de subjetivação no campo de pesquisa, permitindo que a coleta de informações deixe de estar restrita ao domínio da representação e, assim, permita um procedimento de análise 
pelo qual a realidade a ser estudada está em constante transformação e movimento, uma realidade composta por diferentes narrativas, contextos e linhas de força a serem considerados em sua complexidade e singularidade ${ }^{20,21}$. Por meio do referencial da micropolítica, buscou-se acessar as experiências tais como foram vivenciadas pelos participantes e, nos encontros intercessores entre pesquisadores e entrevistados, permitir distintas possibilidades de subjetivação e singularização, além de trocas de saberes e fazeres em um processo que incluía a dimensão pedagógica ${ }^{22}$. Assim, tornou-se possível cartografar não somente a subjetividade do outro, mas também afecçóes e transformações mútuas, incluindo as dos pesquisadores, e o produto desta cartografia foi extensamente registrado em diário de campo.

No decorrer da pesquisa algumas análises preliminares do material empírico indicavam, como veremos na seção seguinte, uma codificação definida por um certo "ser médico", demandando um outro conceito-ferramenta do referencial da micropolítica: o "território identitário ou existencial”23,24. Tal conceito já havia sido utilizado em uma pesquisa anterior ${ }^{25}$ para se compreender de que modo a repetição histórico-social de alguns conjuntos discursivos produz um corpo normativo para o agir/viver, conjuntos esses que são compostos por referentes significantes (naquela pesquisa "ser profissional de saúde") e valores transcendentes (nesta pesquisa "como deve ser e agir o profissional de saúde" ${ }^{23,24}$. O conceito de território existencial identitário ou autorreferenciado sustentase no pressuposto de que a significância da comunicação, que não dissocia expressão e conteúdo, está envolta em processos de subjetivação ${ }^{23-25}$.

Se dizer sobre uma identidade ou agir de acordo com ela é fazê-la existir, também pode acontecer a desconstituição desse território identitário mediante "desterritorializaçôes", ou saídas para outras significaçóes, mudando total ou parcialmente os limites da atual identidade no sentido de novas "reterritorializaçôes" ${ }^{24}$. Acrescente-se que a pesquisadora/ autora principal é médica de Família e Comunidade, em plena atuação profissional durante a realização do trabalho de campo da pesquisa, e que, por estar cursando um mestrado profissional, ela própria vivenciou cotidianamente situaçóes e sentimentos muitos semelhantes aos que investigava.

Este estudo foi aprovado por Comitê de Ética em Pesquisa (CAAE n.

78685517.3.0000.0102).

\section{Resultados e discussão}

Foram entrevistados dez médicos, sendo quatro médicos residentes (MR) com até 29 anos de idade; três "médicos jovens" (MJ) com idades entre 31 e 37 anos; e três médicos experientes (ME) com idades entre 55 e 62 anos. Eram quatro mulheres e seis homens, com tempo de conclusão do curso de Medicina que variou de dois a 36 anos e tempo de atuação na mesma unidade de saúde de um a 18 anos. A pesquisadora principal, ao entrevistar colegas de especialidade e de cenários de trabalho, embora não tenha sido ela própria entrevistada, colocou-se ao mesmo tempo como pesquisadora e participante da pesquisa quando das análises aqui dispostas, um entrelugar que a abordagem cartográfica lhe permitiu, posto que o "ser médica" é uma identidade existencial que também a constitui como sujeito. 
Todos os entrevistados trouxeram em suas falas elementos que relacionamos a um "território identitário médico" ou "identidade médica", um conjunto de enunciados que oferecem valores e convicções normatizadoras do comportamento cuja repetição cotidiana legitima suas ações como profissionais ao estruturar um pertencimento a essa profissão. Como exemplos, identificamos expressões como "o escopo da medicina", o "feijão com arroz do fazer medicina", o "ser médico", como mostram alguns dos trechos a seguir:

Eu sinto que é mais fácil ir além e não fazer só aquele 'feijão com arroz', isso dá uma realização plena, mais intensa nessa parte da vida, a profissional. (fragmento da entrevista com MR3, grifo nosso)

É uma relação que transcende muito a relação médico-paciente, e isso já faz tempo, que a gente tem esse tipo de relação... diria assim, sai do escopo do 'só médico', pra se preocupar com a vida das pessoas, eu com a vida deles e eles com a minha. (fragmento da entrevista com ME1, grifo nosso)

Tais enunciaçôes mostram que a ideia do "ser médico" pressupóe um determinado código que se concretiza no território pelo qual o médico fala e no qual compreende a si mesmo: tudo o que extrapola tais limites configuraria um "além do ser médico". Possivelmente, mesmo antes de sua formação médica o sujeito já traz em si os elementos que compóem tal território, com base em sua história de vida, cultura, crenças, experiências vividas, que orbitam ao redor do tema "Medicina"26,27. A identidade médica, portanto, é uma construção que não é exclusiva da formação universitária desse profissional.

A constituição do que seria uma "identidade médica” se expressa nessas enunciações mostrando que, para a totalidade dos entrevistados, há um pressuposto de que para exercer essa profissão seria preciso seguir uma determinada forma de agir, de ser, de pensar. Tais conceitos trazem elementos que remontam às origens da Medicina como se vê, por exemplo, na filosofia de Avicena, médico persa da Idade Média que enumerou as muitas aptidóes esperadas daquele que exercia a medicina, como:

[...] possuir um olhar agudo, ouvido apurado, uma cabeça lúcida e um espírito crítico [...] deve ser sadio de alma e corpo [...] deve ter uma aparência externa conveniente e bons $\operatorname{modos}^{28}$. (p. 32)

[...] ou no juramento hipocrático, que reza: 'conservarei imaculada a minha vida e minha alma ${ }^{26}$. (p. 441)

É na Idade Média que o "ser médico" começa a se definir no contexto social, com o exercício da Medicina passando a ser regulamentado por leis e a necessidade de concessão de grau ${ }^{28}$. A partir daí a figura do médico passa a ter uma expressão social maior, pois o médico respalda sua prática em métodos e técnicas baseados no 
conhecimento científico que "pertence" à Medicina ${ }^{28}$. A ideia do médico onipotente, altruísta e com poder sobre vida e morte caminha para uma pronunciada idealização da profissão $0^{26-28}$. Nesse sentido, grande parte dos entrevistados interpreta suas ações como um exercício do seu poder como médicos, e reconhecem que há um sentimento de onipotência que permeia a sua prática profissional, seja pela atitude dos próprios médicos para com seus usuários, seja pela atitude dos usuários, da sociedade ou de instituiçôes com relação ao médico:

Você tem que decidir o tempo todo coisas muito importantes para aquelas pessoas que às vezes podem suscitar até doenças mais graves, vida ou morte. (fragmento da entrevista com MR3, grifo nosso)

[...] quando você vê o paciente numa situação de sofrimento emocional, social, de bastante dificuldade, isso te gera um compadecimento, ao mesmo tempo um desejo de mudar e mexer com o teu poder, e ser centralizador do poder médico, a gente tem um poder sobre a vida dessas pessoas. [...] e esse sofrimento, essa dor, quando fere meu ego, esse ego médico, a dor desse ser onipotente que a gente veste enquanto medicina. (fragmento da entrevista com MJ3, grifos nossos)

[...] Hoje mesmo uma paciente falou: "poxa vida, doutora, nem parece que é médica 'né', faz tudo isso e ainda 'tá' no mesmo nível que a gente!” (fragmento da entrevista com ME3, grifo nosso)

Jeammet et al..$^{29}$ citam aspectos da relação de poder entre médico e usuário, em que o primeiro se encontra em uma posição de "autoridade esclarecida" por ser portador do conhecimento para a cura. Maldonado ${ }^{30}$ comenta sobre a crença de que o profissional só será digno de respeito e confiança ao se colocar como uma pessoa forte e onipotente e, mais do que isso, que haveria o desejo por parte dos médicos de criar uma aura de mistério acerca de seus procedimentos, adotando uma conduta autoritária e com menos possibilidades de questionamentos. Se, ao contrário, acontece uma aproximação, uma atitude cuidadora, então "nem parece que é médica”, como cita ME3.

A ideia de onipotência intrínseca ao território identitário do médico não apenas vai refletir em suas relações de poder com outros sujeitos, mas também na forma como o médico encara a si mesmo, na maneira que vivencia sentimentos como o medo de errar, a culpa por uma falha presumida, a vergonha por não atender às expectativas ou mesmo a dificuldade em manter-se emocionalmente intacto para não se revelar frágil diante do outro, e comprometer seu juízo perante as decisôes a serem tomadas ${ }^{31}$.

O Código de Hamurábi, rei babilônio do século 18 a.C., previa que o médico que errasse um diagnóstico ou tratamento deveria ter suas mãos amputadas como forma de punição pelo erro ${ }^{28}$. Figurativamente, a "amputação" que um médico sofre ao compreender que sua onipotência não é tão perfeita e exata como acreditava pode levar a um processo de desterritorialização: uma descontinuação do território 
autorreferenciado tal como proposto por Guattari e Deleuze \& Guattari ${ }^{23,24}$. Muitas vezes o gatilho da desterritorialização pode ser uma experiência de perda - seja da infalibilidade, seja da inafetabilidade:

[...] a gente tem um poder sobre a vida dessas pessoas, o que também pode trazer uma sensação de impotência, porque esse poder também é limitado. (fragmento $\mathrm{da}$ entrevista com MJ3, grifo nosso)

[...] mas o paciente acabou falecendo, assim... isso me deu um... um sentimento muito ruim, um sentimento de perda, um sentimento de impotência, porque eu vi esse paciente várias vezes, e independente de eu ter visto ele tantas vezes assim parece que não foi o suficiente, ou não salvou a vida dele, digamos assim, 'né'? (fragmento da entrevista com MR4, grifo nosso)

Eu tento não demonstrar o sentimento, mas eu sinto! 'Tô' compartilhando um momento de sofrimento com a família que é um sofrimento meu também, eu já tinha afeto por aquele paciente. [...] E a tristeza, o pesar...existe uma sensação de perda, por uma questão afetiva. Mas tem uma sensação de perda quando a gente vê que falhou... aí você fica se sentindo o pior médico do mundo, 'né'? Porque, puxa vida, ela não podia ter morrido, 'né'? (fragmento da entrevista com ME3, grifo nosso)

O vínculo com o usuário, nesses casos, também trouxe abertura a uma outra desterritorialização, pois, além de ter de encarar a realidade de sua própria imperfeição, havia um fator a mais produzindo sentimentos inquietantes: a dor do outro que, por meio do encontro intercessor, ${ }^{4}$ permitiu ao médico um olhar para além do puramente técnico ou profissional. Schultz et al. ${ }^{16}$ descrevem que o vínculo e a continuidade do cuidado podem produzir nos médicos de família um desgaste emocional, especialmente quando há um contato frequente com o sofrimento do usuário ou as tentativas de solucionar tal sofrimento são malsucedidas. Da Silva \& Teixeira ${ }^{31}$ citam que “o médico é visto (até mesmo por ele próprio) como aquele que deve saber e, se não sabe, é porque não é um bom médico" (p. 6). Nas entrevistas, alguns médicos relataram que o sofrimento vivenciado trouxe de fato questionamentos quanto à capacidade profissional, e até mesmo o desejo de desistir da Medicina:

Tem casos que acabam sempre ficando marcados, e que pra mim trouxeram uma ansiedade tão grande a ponto de eu questionar a minha capacidade profissional, a minha profissão, se eu 'tava' na profissão certa, inclusive pensar em abandonar, em sair dessa área, ir pra outra, às vezes até mudar de profissão. (fragmento da entrevista com MJ1, grifo nosso)

Diversos autores ${ }^{17,32-34}$ comentam sobre a possibilidade de um endurecimento profissional por parte daqueles que, ao tentarem lidar com instabilidades e incertezas $\mathrm{da}$ profissão, entenderam que o distanciamento da dor do outro seria um caminho mais 
seguro. Refugiam-se na racionalidade, no tecnicismo, nas tecnologias duras e leveduras ${ }^{4}$, diríamos. Alguns podem até experimentar um quadro de despersonalização, uma indiferença emocional, além de sentimentos negativos com relação aos usuários ${ }^{33}$.

Reconhecer e analisar o próprio território identitário pode ser um caminho para outro reconhecimento, e possivelmente isso se dê com o passar dos anos, à medida que o médico vivencia diferentes situaçóes que o colocam diante das quebras em seu território. Com efeito, a maioria dos médicos que trouxeram para a entrevista elementos de uma reconfiguração do território existencial era de MJ (acima de 31 anos) e "experientes". Os médicos residentes foram menos explícitos nesse sentido.

Tais fatos levantam alguns questionamentos: seria possível trabalhar ainda na formação médica os aspectos inquietantes do território identitário médico, a fim de diminuir o sofrimento e possibilitar um alargamento desse território, uma flexibilização dele proporcionando mais satisfação tanto para o médico como para o usuário nos momentos de desterritorialização? Como apoiar os médicos no sentido de uma reterritorialização em um território mais cuidador de si e do outro, em uma perspectiva "usuário-centrada"?

Alguns desses pontos têm sido trabalhados em programas de residência médica quando há estímulo ao desenvolvimento de habilidades de comunicação, ao desenvolvimento de vínculo, ao reconhecimento do usuário como objeto central do cuidado, a exemplo do MCCP2,13,32,35. Há também experiências de incentivo dos residentes e médicos especialistas ao autoconhecimento e ao autocuidado, por meio de psicoterapia, participação em grupos Balint, estímulo a práticas que possam diminuir a sobrecarga emocional, como o contato com a arte, o exercício da espiritualidade, ou pelas Práticas Integrativas e Complementares (Pics) $)^{18,19,32,34,36}$. Tais estratégias foram também citadas pelos entrevistados:

Há outras coisas do mundo que nos fazem sentir humanos de volta, então por exemplo a arte, a arte é um meio de entrarmos em contato com o que é humano na gente, estar vendo filmes, assistindo, vendo pinturas, ouvindo música, vivenciando a arte, o teatro, são ferramentas de a gente conseguir ressignificar [o sofrimento]. [...] e quando você tem alguma fé, em algum paradigma, que explique os porquês da vida, existe onde se agarrar. (fragmento da entrevista com MJ3, grifos nossos)

[...] algo que a gente já tinha discutido na residência, sobre comunicação, [grupos] Balint, eu acho que você falando você também cresce, você entende melhor, consegue trabalhar essas questôes. (fragmento da entrevista com MR3, grifo nosso)

Muito mais do que um esforço em se distanciar de seus usuários, a desterritorialização experimentada (e permitida) pelos entrevistados possibilitou reconstruçóes do território médico em outras configuraçôes, com a produção de territórios por vezes mais cuidadores de si e do outro. É quando essa busca por rearranjar o território existencial aponta para uma reterritorialização em um outro lugar, um deslocamento para um "lugar cuidador" 
[...] essa proximidade deixa a gente muito vulnerável, 'né', aquele mito do médico, o cara que é intocável, acaba. Então a chance das críticas e das quebras de expectativas em relação a mim é muito maior... então eu me sinto mais vulnerável nesse sentido, mas isso não me fragiliza, o que me dá sustentação é a minha capacidade técnica também, e nesse sentido eu preciso cada vez mais estar estudando, fazer negociações, tudo é compartilhado, tudo para me dar segurança. [...] (fragmento da entrevista com ME3, grifo nosso)

Essa fala exemplifica o movimento do médico em direção a uma reterritorialização em que se reconhecer vulnerável se torna algo aceitável e até mesmo desejável. Permitese, então, um deslocamento que extrapola o indivíduo e se torna um processo coletivo: um outro "ser médico" é possível tanto para o profissional como para o usuário. E o vínculo, fortalecido no encontro intercessor, é capaz de produzir no médico sentimentos de satisfação, realização, pertença. Nesse processo de um outro reconhecimento de si, compreende-se que o papel do médico vinculado aos seus usuários transcende possíveis desfechos que sejam medidos somente pelas tecnologias duras e leve-duras ${ }^{3,4}$ :

[...] e a pessoa vai viver ou vai morrer independente de como as outras pessoas agirem, são as regras do jogo, e o jogo 'tá' posto, a gente não é dono do tabuleiro, a gente 'tá' só sendo mais um peão, a gente pode ser um peão consciente com muito potencial, com muita noção do seu potencial... a gente é dispensável, a gente é inútil, ao aceitar isso a gente consegue estar naquele lugar consciente de nossa pequeneza e com essa consciência aumenta o nosso potencial de ajuda, de cura e nos tranquiliza. (fragmento da entrevista com MJ3, grifo nosso)

Caprara \& Rodrigues ${ }^{13}$ discorrem sobre a relação assimétrica existente entre médico e usuário, no sentido de que o médico é o detentor da totalidade do conhecimento do qual o usuário é geralmente excluído. Seixas et al. ${ }^{7}$ reforçam o papel do vínculo no estabelecimento de relaçôes simétricas, nas quais o usuário da saúde é encarado como um interlocutor válido, e cujos saberes têm igual ou maior importância na construção do cuidado. A posição de controlador sobre a vida do outro dá, então, lugar a uma desterritorialização capaz de potencializar o processo autoanalítico da produção do cuidado, desconstruindo a figura do médico onipotente e produzindo encontros com simetria de poder.

Especialmente quando se fala de um vínculo constituído de simetria de poder e saber, a desconstrução da imagem do médico infalível traz consigo um potencial tranquilizador. Muitos entrevistados relataram se sentir mais seguros por estarem vinculados aos usuários, com menos medo de falhar e maior potência no enfrentamento de problemas, ao passo que a idealização do médico onipotente se desfaz:

[...] eu também sou falível, eu posso errar, mas o vínculo forte me dá mais segurança para poder exercitar a Medicina da melhor forma possível, e também com mais tranquilidade se porventura eu errar. (fragmento da entrevista com ME3, grifo nosso) 
Lidar com incerteza a gente lida sempre, mas o vínculo faz essa incerteza ficar um pouco mais fácil de ser manejada. (fragmento da entrevista com MJ1, grifo nosso)

E mais do que isso, o vínculo se estabelece como terreno fértil para que o encontro intercessor aconteça e se traduza em cuidado, em que os sujeitos abrem mão da posição de domínio sobre o outro e se entregam a uma construção compartilhada do cuidado, permitindo-se revelar seus não saberes e ser afetado não apenas pelo sofrimento e pela fragilidade, mas especialmente pela potência de vida do outro ${ }^{4,7}$. E para o médico que está diariamente exposto às dificuldades da profissão, saber-se vinculado aos seus usuários pode desempenhar um papel revigorador mais do que desgastante. A simetria que produz vínculo vai além das relações de saber e poder e se torna uma "simetria de cuidado": o médico ganha potência no agir por sentir-se vinculado ao seu usuário, produzindo novas possibilidades de cuidado do outro e de si mesmo, entendendo que quem fornece o cuidado também pode recebê-lo em um mesmo ato, pois se trata de um encontro intercessor:

[...] mas a gente que está todo dia na APS com a população, a gente sofre junto. Você cria vínculo, cria vínculo. Sofre junto, mas isso, por outro lado, é a recompensa que a gente tem, de se sentir próximo. (fragmento da entrevista com ME2, grifo nosso)

Como a gente se sente também às vezes acolhido pelo paciente, quando o paciente vê que a gente 'tá' cansado, não 'tá' bem, eles fazem o papel terapêutico com a gente, isso nos traz uma sensação de pertencimento, uma sensação de estar presente na comunidade, de ser humano, e ser além de médico, outra pessoa ali junto com ele. [...] aí eu tenho que entrar em contato comigo e lembrar que humano sofre, aceitar minha falha, aceitar a falha do outro, aceitar a dor que 'tá' na humanidade e pra lidar com essa dor aí eu preciso de ferramentas, eu preciso de ter contato com pessoas com as quais eu possa compartilhar essa dor, e o contato com o próprio paciente, aí o mesmo vínculo que é o que me causa o peso, é o vínculo que me dá o alívio pra essa dor, então o vínculo que me dói e que me pesa diante do sofrimento é o mesmo vínculo que alimenta a minha [própria] cura. (fragmento da entrevista com MJ3, grifos nossos)

Ao vivenciar o vínculo, e para vivenciá-lo em toda sua intensidade, o médico tem a oportunidade de deixar para trás os rótulos de onipotente, inacessível, infalível, permitindo a si mesmo experimentar esse encontro sem preconceitos e/ou expectativas definidos. Nesse movimento, tanto médico como usuário passam a transitar pela dimensão cuidadora do encontro, em um espaço em que ambos se permitem ouvir e serem ouvidos, cuidar e serem cuidados. O próprio vínculo estimula a reconstrução de um novo território existencial com mais potência, que vai muito além de uma repetição discursiva frágil, imposta, inquestionada. Tal potência vem do encontro assim vivenciado, e leva a uma desativação daquele território identitário que antes parecia sólido, blindado, imutável. Dessa 
forma, as tecnologias leves, já decisivas no processo de desterritorialização que se efetiva, agora passam a ser operadas com ainda mais facilidade, e o encontro cuidador se materializa em um território preenchido por novas possibilidades de configuraçóes do cuidado de si e do outro.

\section{Considerações finais}

As origens do território identitário médico remontam às origens da própria humanidade, possuindo elementos que dão corpo à ideia de poder e infalibilidade do médico. De diversas formas o médico pode vivenciar uma desconstrução de seu território existencial autorreferenciado, percebendo-se impotente, falível, imperfeito. O resultado disso pode ser um endurecimento, como que uma tentativa de evitar a descontinuação de seu lugar de onipotência, reterritorializando-se em um reforço identitário do "ser médico". Ou, quando outra desterritorialização acontece, pode levar a sentimentos de sofrimento e angústia, e adoecimentos.

Por outro lado, no contexto do encontro intercessor o médico vivencia, nos atos de cuidado em saúde, a possibilidade do vínculo com seus usuários, e com base em vínculos simétricos podem ocorrer reterritorializações nas quais o médico assume seus não saberes e se desfaz da ideia de onipotente para trilhar um novo terreno com seu paciente: um encontro cuidador.

Por mais estanque que a identidade médica socialmente aceita pareça ser, o território identitário médico pode ser parcialmente desativado e desviado em outras reterritorializaçóes de forma dinâmica e constante. Seja por desarmar-se de uma postura de infalibilidade, seja por reconhecer o poder e o saber do outro (usuário, equipe), seja por permitir-se afetar pelos sentimentos do outro e reconhecer que há potência de agir nesse encontro, o médico pode então se valer de suas vivências na reconstrução de sua identidade profissional.

Sobretudo o vínculo desempenhará um papel central nas reterritorializaçóes, à medida que o médico incorpore como um novo valor a potência do encontro cuidador para si e para o outro. Como placas tectônicas em movimento, o território identitário médico poderá, então, assumir um caráter dinâmico, produzindo desvios e novas configuraçóes do “fazer Medicina”, numa constante transformação em que as tecnologias leves poderão ser intensamente operadas no âmbito do encontro cuidador. 


\section{Contribuições dos autores}

Todos os autores participaram ativamente de todas as etapas de elaboração do manuscrito.

\section{Conflito de interesse}

Os autores não têm conflito de interesse a declarar.

\section{Direitos autorais}

Este artigo está licenciado sob a Licença Internacional Creative Commons 4.0, tipo BY (https://creativecommons.org/licenses/by/4.0/deed.pt_BR).

\section{(cc) BY}

\section{Editor}

Antonio Pithon Cyrino

Editor associado

Leandro David Wenceslau

Submetido em

09/06/20

Aprovado em

$20 / 11 / 20$

\section{Referências}

1. McWhinney IR, Freeman T. Textbook of family medicine. New York: Oxford University Press; 2009.

2. Stewart M, Brown JB, Weston WW, McWhinney IR, McWilliam CL, Freeman TR. Medicina centrada na pessoa: transformando o método clínico. 3a ed. Porto Alegre: Artmed; 2017.

3. Merhy EE. O ato de cuidar: a alma dos serviços de saúde. In: Brasil. Ministério da Saúde. Secretaria de Gestão do Trabalho e Educação na Saúde. Departamento de Gestão da Educação na Saúde. Ver-SUS Brasil: caderno de textos. Brasília: Ministério da Saúde; 2004. p. 108-37.

4. Merhy EE. O cuidado é um acontecimento e não um ato. Trabalho, produção do cuidado e subjetividade em saúde: textos reunidos. São Paulo: Hucitec; 2013.

5. Starfield B. Atenção primária: equilíbrio entre necessidades de saúde, serviços e tecnologia. Brasília: Unesco, Ministério da Saúde; 2002. 
6. Campos CEA. Os princípios da Medicina de Família e Comunidade. Rev APS. 2005; 8(2):181-90.

7. Seixas CT, Baduy RS, Cruz KT, Bortoletto MSS, Slomp Junior H, Merhy EE. O vínculo como potência para a produção do cuidado em saúde: o que usuários-guia nos ensinam. Interface (Botucatu). 2019; 23:e170627.

8. Brasil. Ministério da Saúde. Saúde da Família: uma estratégia para a reorientação do modelo assistencial. Brasília: Ministério da Saúde; 1997.

9. Brasil. Ministério da Saúde. Portaria no 2.488, de 21 de Outubro de 2011. Aprova a Política Nacional de Atenção Básica, estabelecendo a revisão de diretrizes e normas para a organização da Atenção Básica, para a Estratégia Saúde da Família (ESF) e o Programa de Agentes Comunitários de Saúde (PACS). Brasília: Ministério da Saúde; 2011.

10. Franco TB, Bueno WS, Merhy EE. O acolhimento e os processos de trabalho em saúde: o caso de Betim, Minas Gerais, Brasil. Cad Saude Publica. 1999; 15(2):345-53.

11. Brunello MEF, Ponce MAZ, Assis EG, Andrade RLP, Scatena LM, Palha PF. O vínculo na atenção à saúde: revisão sistematizada na literatura, Brasil (1998-2007). Acta Paul Enferm. 2010; 23(1):131-5.

12. Mainous AG, Baker R, Love MM, Gray DP, Gill JM. Continuity of care and trust in one's physician: evidence from primary care in the United States and the United Kingdom. Fam Med. 2001; 33(1):22-7.

13. Caprara A, Rodrigues JV. A relação assimétrica médico paciente: repensando o vínculo terapêutico. Cienc Saude Colet. 2004; 9(1):139-46.

14. Sans-Corrales M, Pujol-Ribera E, Gene-Badia J, Pasarin-Rua MI, Iglesias-Perez B, Casajuana-Brunet J. Family medicine attributes related to satisfaction, health and costs. Fam Pract. 2006; 23(3):308-16.

15. Frederiksen HB, Kragstrup J, Dehlholm-Lambertsen G. It's all about recognition! Qualitative study of the value of interpersonal continuity in general practice. BMC Fam Pract. 2009; 10:47.

16. Schultz K, Delva D, Kerr J. Emotional effects of continuity of care on family physicians and the therapeutic relationship. Can Fam Physician. 2012; 58(2):178-85.

17. Ramirez AJ, Graham J, Richards MA, Cull A, Gregory WM. Mental health of hospital consultants: the effects of stress and satisfaction at work. Lancet. 1996; 347(9003):724-8.

18. Puffer JC, Knight HC, O’Neill TR, Rassolian M, Bazemore AW, Peterson LE. Prevalence of burnout in board certified family physicians. J Am Board Fam Med. 2017; 30(2):125-6.

19. Visser MR, Smets EM, Oort FJ, De Haes HC. Stress, satisfaction and burnout among Dutch medical specialists. CMAJ. 2003; 168(3):271-5.

20. Kastrup V. O funcionamento da atenção no trabalho do cartógrafo. Psicol Soc. 2007; $19(1): 15-22$.

21. Passos E, Kastrup V, Escóssia L. Pistas do método da cartografia: pesquisa intervenção e produção de subjetividade. 4a ed. Porto Alegre: Sulina; 2015.

22. Guattari F, Rolnik S. Micropolítica: cartografias do desejo. Petrópolis: Editora Vozes; 2000.

23. Deleuze G, Guattari F. Mil platôs - capitalismo e esquizofrenia. Rio de Janeiro: Editora 34; 1995. (Coleção Trans(2)). 
24. Guattari F. Caosmose: um novo paradigma estético. São Paulo: Editora 34; 1992. (Coleção Trans).

25. Slomp Junior H, Feuerwerker LCM, Land MGP. Educação em saúde ou projeto terapêutico compartilhado? O cuidado extravasa a dimensão pedagógica. Cienc Saude Colet. 2015; 20(2):537-46.

26. Pessotti I. A formação humanística do médico. Medicina (Ribeirão Preto). 1996; 29(4):440-8.

27. Ramos-Cerqueira ATA, Lima MCP. A formação da identidade do médico: implicaçôes para o ensino de graduação em Medicina. Interface (Botucatu). 2002; 6(11):107-16.

28. Hoirisch A. Ser médico, implicaçôes históricas e antropológicas. São Paulo: Casa do Psicólogo; 2006.

29. Jeammet P, Reynaud M, Consoli S. Manual de psicologia médica. Rio de Janeiro: Medsi; 2000.

30. Maldonado MTP. A ilusão de onipotência na relação médico-cliente. Cienc Consciencia. 1978: 324-31.

31. Da Silva ALP, Teixeira MAA. A angústia médica: reflexôes acerca do sofrimento de quem cura. Cogitare Enferm. 2002; 7(1):75-83.

32. Balint M. O médico, seu paciente e a doença. Rio de Janeiro: Atheneu; 1988.

33. Romani M, Ashkar K. Burnout among physicians. Libyan J Med. 2014; 9:23556.

34. Gonçalves CIRVB. Síndrome de Burnout em estudantes de medicina [tese]. Porto, PT: Instituto de Ciências Biomédicas Abel Salazar, Universidade do Porto Centro; 2016.

35. Ribeiro MMF, Amaral CFS. Medicina centrada no paciente e ensino médico: a importância do cuidado com a pessoa e o poder médico. Rev Bras Educ Med. 2008; 32(1):90-7.

36. Tesser CD, Sousa IMCD. Atenção primária, atenção psicossocial, práticas integrativas e complementares e suas afinidades eletivas. Saude Soc. 2012; 21(2):336-50. 
The purpose of this qualitative research with a cartographic approach was to understand the effects that bonding and accountability between family physicians and users can produce on the physicians themselves. Ten open interviews were conducted based on triggering questions with family physicians and medical residents. The analysis of the interviews using the reference of the micropolitics was based on the experiences reported, and it was problematized the existence of a "medical identity territory", as well as the deconstruction of this territory, its "deterritorialization", leading to "reterritorializations", such as moving away from omnipotence / infallibility not to suffer, but to take care of oneself and others. It is proposed that in this movement, both physician and user start to move through the caregiving dimension of the encounter, where light technologies can be operated and new possibilities of configurations of care happens.

Keywords: Family practice. Continuity of patient care. Bond. Patient-Centered Care.

Estudio cualitativo con abordaje cartográfico cuyo objetivo fue comprender los efectos que el vínculo y la toma de responsabilidad entre médicos de familia y usuarios producen en los propios médicos. Se realizaron diez entrevistas abiertas a partir de preguntas desencadenadoras con médicos de familia y médicos residentes. El análisis de las entrevistas se realizó con base en el referencial de la micropolítica y problematizó, a partir de las experiencias relatadas, la existencia de un "territorio de identidad médico", así como las posibilidades de desconstitución de este territorio, su desterritorialización en el sentido de nuevas reterritorializaciones, con el ejemplo de apartarse de la omnipotencia/infalibilidad no para sufrir, sino para cuidar de sí mismo y del otro. Se propone que, en ese movimiento de reconstrucción del territorio de identidad, tanto el médico como el usuario pasan a transitar por la dimensión cuidadora del encuentro, en donde tecnologías leves pueden operar y suceden nuevas posibilidades de configuraciones del cuidado.

Palabras clave: Medicina de familia y comunidad. Longitudinalidad del cuidado. Vínculo. Cuidado centrado en el paciente. 